\title{
COMPARING TRANSLATION PECULIARITIES OF LEGAL TEXTS IN THE RUSSIAN AND PERSIAN LANGUAGES
}

\author{
V. Rezvani \\ Sheikhbahayi Square st. Alzahra University, Faculty of Literature \\ Tehran, Iran
}

\begin{abstract}
Translation of legal texts requires special attention and great accuracy. In legal texts words have legal connotations and legal consequences, which enable either to protect the interests of legal entities and individuals, or, on the contrary, violate their rights. Inappropriate translations of legal texts cause misunderstanding and vagueness, which is unacceptable in this type of texts. The compendium of legal texts in Iran is based on general legal law and jurisprudential principles. The lack of bilingual legal RussianPersian and Persian-Russian dictionaries enhances the translation problems in this field. This fact suggests that due attention has not been paid to such an important issue in the field of linguistics. The current criterion used in the translation of legal documents is the objective interpretation of the text. The identification of the problem can help solve it. The subject of this article was the legal content focused on legal family and financial texts. The purpose of our research is to reveal the difficulties translators of legal texts in these languages face, to study the best examples of translation accumulated by far and to help translators of legal texts by integrating translators' experiences and publishing comparative works that reveal cultural and semantic connotations in two languages.
\end{abstract}

Key Words: translation, legal, Russian, Persian, comparison, translation problems, bilingual dictionaries

For citation: Rezvani V., 2021. Comparing Translation Peculiarities of Legal Texts in The Russian and Persian Languages. Philological Sciences at MGIMO.Vol. 7. No 1(25). P. 111-118. https://doi. org/10.24833/2410-2423-2021-1-25-111-118

\section{СОПОСТАВЛЕНИЕ ОСОБЕННОСТЕЙ ПЕРЕВОДА ЮРИДИЧЕСКИХ ТЕКСТОВ НА БАЗЕ РУССКОГО И ПЕРСИДСКОГО ЯЗЫКОВ}

\section{В. Резвани}

Тегеран, Иран

Площадь Шейхбахайи, Университет Аль-Захра 
Аннотация. Перевод юридических текстов требует большой точности и особого внимания. В юридических текстах слова имеют правовую коннотацию и правовые последствия, которые либо способствуют защите интересов юридических и физических лии, либо, наоборот, приводят к нарушению прав граждан. Неточные переводы юридических текстов вызывают недопонимание и распльвчатость, что недопустимо в этом виде текстов. Компендиум юридических текстов в Иране создан на базе общего правового закона и юридических принципов. Отсутствие двуязычных юридических русско-персидских или персидско-русских словарей осложняет перевод текстов юридического профиля, что свидетельствует о том, что до сих пор не было уделено должного внимания профессиональному переводу в области юриспрудениии. Вследствие этого переводчики ориентируются только на интерпретацию терминов. Объектом рассмотрения в данной статье послужили юридические документы, в которых отражаются правовые решения семейных и финансовых проблем. Цель настоящей работь - знакомство с трудностями перевода юридических текстов в упомянутых языках, учёт опыта, накопленного предыцущими поколениями, а также рекомендации для переводчиков юридических текстов, которые видятся в интеграции опыта переводчиков и наряду с этим - издании сопоставительных трудов, раскрывающих культурные и смысловые коннотации.

Ключевые слова: юридический перевод, юриспруденция, русский язык, персидский язык, сопоставление, трудности перевода, двуязычные словари

Для цитирования: Резвани В., 2021. Сопоставление особенностей перевода юридических текстов на базе русского и персидского языков. Филологические науки в МГИМО. Том 7. № 1(25).

C. 111-118. https://doi.org/10.24833/2410-2423-2021-1-25-111-118

\section{Введение}

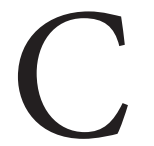

расширением круга международного общения интерес и необходимость в подготовке специальных переводчиков в сфере профессиональной коммуникации повышается. Юридические тексты на персидском языке имеют существенные отличия из-за различий в структуре судебной системы Ирана и российской судебной системы, поэтому этот момент следует учитывать при обучении переводчиков. Актуальность настоящего исследования заключается в определении перевода юридических текстов как одного из стилей официального перевода и рассмотрении способов снижения его расплывчатости и неточности. В процессе изучения персидских и русских юридических текстов сопоставительным методом мы рассчитываем найти надёжный способ передачи правовой коннотации в указанных текстах. Материалом, используемым для изучения, послужили юридические документы различного профиля, такие как договоры, сертификаты, доверенности и т.п. в Иране и России.

\section{Основное содержание}

Значение юридического языка становится очевидным, если учесть его связь с человеческой деятельностью. Слова - это не только средства выражения, но и также инструменты действия. Язык закона - это не просто обозначение

объектов, но это язык будущих действий. Юридический язык - это проекция в будущее, которая позволяет предвидеть и предсказывать человеческое поведение со степенью уверенности, необходимой для социальной жизни.

То, что юридический перевод в области международного права имеет большое значение, очевидно во многих отношениях.

Важным аспектом теории юридического перевода является определение качества переведённого текста. Точность перевода включает не только соответствие тексту, но и сохранение смысла 
контекста. Опытный переводчик должен отслеживать любые изменения контекста между написанием текста и его интерпретацией.

Если в тексте смысл является определяющим для однозначного восприятия любого высказывания, то контекстуальные условия, которые предшествуют или следуют за этим высказыванием, будут скрывать этот смысл. Для того чтобы смысл был сохранён, необходимо следить за соблюдением обоих условий.

Переводчик должен понимать как правовую культуру, в которой был создан исходный текст, так и правовую культуру, к которой будет применяться итоговый текст. Необходимость знакомства со специализированной терминологией показывает, что только переводчик, знакомый с правовыми системами обеих стран, может справиться с поставленной задачей.

Переводчики, не специализирующиеся на праве, даже с высочайшим уровнем языковых знаний, просто не в состоянии перевести юридические тексты. Иногда обычные события, объекты и концепции, попадая в область правового мира, претерпевают значительные трансформации. Например, слову «лицо» присвоено много значений в разных словарях, из которых приведём лишь основные, опираясь на словарь Ожегова: сементическое (медицинское): передняя часть головы человека; грамматическое: категория, показывающая отнесённость к говорящему, к собеседнику или к тому, кто не является ни говорящим, ни собеседником; юридическое: самостоятельная организация, обладающая имущественными и другими гражданскими правами и обязанностями. Другие значения либо прямо выводятся из перечисленных значений, либо переносные.

Как правило, правовым системам любого государства присущи специальные термины, возникающие в соответствующих историко-культурных условиях и не встречающиеся в других правовых системах. Проблема передачи содержания, обозначаемых ими правовых понятий заключается в том, могут ли существующие переводы вызывать адекватное восприятие у носителей языка перевода. Как было уже отмечено А.С. Киндеркнехтом, «основные трудности в переводе юридических текстов связаны, как правило, с интерпретацией профессиональной юридической терминологии. Именно трактовка терминов и стоящих за ними юридических понятий в данной конкретной системе права - камень преткновения начинающих переводчиков» [3, с. 123]. Один из наиболее эффективных путей избежать проблем и двусмысленности при переводе - проведение консультации с опытными специалистами в области права и сопоставление с аутентичными документами, в которых можно проверить соответствия или процитировать их в качестве первоисточника.

Вот почему перевод юридических документов с персидского языка на русский сопряжён с большими препятствиями, с одной стороны, из-за избыточного количества арабских терминов, укоренившихся в исламской юриспруденции. Согласно ст. 4 Конституции ИРИ, «все гражданские, уголовные, финансовые, экономические, административные, культурные, военные, политические и другие законы и установления должны быть основаны на исламских нормах» [5, c. 59]. Лексика исламских нормативно-правовых актов не имеет эквивалентов в русском языке. С другой стороны, недостаточное количество исследований в сфере специального перевода с персидского языка на русский язык значительно усложняет юридический перевод. Целесообразным считается соблюдение единства процедуры, тексты юридического характера должны иметь «клишированную форму, а информация, содержащаяся в них, должна оформляться раз и навсегда установленным образом, согласно строгим конвенциям» [1, с. 282].

Нельзя упускать из виду, что кроме вышеназванных проблем в переводе документов с юридическим содержанием, исключительно важно сохранить значение переводимого текста, таким образом, чтобы ничьи права не были ущемлены. Нельзя не согласиться с точкой зрения Ю.Э. Гуцу, отметившей, что «без правильной передачи этой системы понятий на языке перевода достижение эквивалентности невозможно. Этим и обусловливается повышенный интерес к вопросам перевода термина, к основным способам достижения адекватного перевода на уровне терминологических слов и словосочетаний» [ 2, с. 27].

Если текст перевода принадлежит совсем другой правовой системе, необходимо будет достичь эквивалентного значения, используя высокую степень интерпретации, гибкости и креативности. 
Переводчики должны найти эквивалентные юридические термины на языке перевода или термины, выполняющие аналогичную юридическую функцию.

К.Ф. Думулан, учитывая сложности юридического перевода с целью устранения проблем и повышения качества в передачи информации на язык перевода, предлагает: «в виду освещения непонятных или ошибочных фрагментов переводимого текста всегда спрашивайте владельца документа», в связи с этим, она придерживается такой точки зрения: «Даже если вы могли своим восприятием достичь значения документа, ни в коем случае не передавайте это значение в своём переводе» $[8$, с. 34]. Это может оказаться непоправимым в силу того, что может представиться невозможным связаться со всеми владельцами документов или же документы могут носить общегражданский или государственный характер. Выход из таких ситуаций мы видим в том, чтобы в разумных пределах прибегать к неологизмам или к транслитерации слов, с соответствующим объяснением или определением, включённым в текст. Вышеуказанные трудности при переводе существуют на общем уровне в любом языке.

Понятие эквивалентности не означает простое копирование слов из исходного текста, а, скорее, означает построение текста на языке перевода таким образом, чтобы он обладал той же силой или значением, что и текст в исходном документе. Лояльность в переводе требует учёта контекста, вне зависимости от дистанционного, временного или географического различия. При переводе юридических терминов, принадлежащих к определённой правовой системе, на язык страны, принадлежащей к другой системе, необходимо найти способ нейтрализовать или, по крайней мере, минимизировать изменение контекста.

Для перевода юридических текстов требуются два основных навыка. Во-первых, необходимо твёрдое лингвистическое знание обеих языковых систем. Также необходимо доскональное знание предмета в соответствующих правовых системах. Эти два условия делают возможным перевод научного текста, несмотря на его сложность, которая заключается в том, что концепции права и правовой политики тесно связаны с соответствующими языковыми системами. Путём перевода с одной языковой системы на другую очень легко изменить информацию, представленную в тексте. В хорошем переводе сохраняется как целостность информации, так и нюансы, присущие каждому языку.

Отличительной чертой языка юридических документов в Иране является изобилие арабских слов и оборотов, мало употребляемых в разговорной речи. Юридические тексты насыщены арабскими конструкциями, в которых включаются номинальные, глагольные и предложные конструкции. В первую очередь, самому переводчику необходимо понять суть изложенного текста, в связи с этим, достаточное знание структуры словообразования арабского языка считается необходимым условием в переводе юридических текстов в судебной системе Ирана. Переводчик, не обладающий достаточной компетенцией в арабской словообразовательной структуре, рискует ошибиться в переводе из-за применения неточного синонимического эквивалента. Например: «khiär» (خيار) в персидском языке означает 'огурец', а в арабском языке означает 'выбор'. "Ghabn» (غبن)в персидском языке означает 'повреждение', а в арабском языке означает 'несправедливость'. «Fähesh» (فاخش) в персидском языке означает 'чрезмерная скверность', а в арабском языке означает 'непристойность'. «Esghät» (اسقاط) как в персидском, так и в арабском языке означает 'отмена', 'лишение’. В качестве примера приведём оборот «Esghät-e khiär-e ghabn-e fähesh» (اسقاط خيار غبن فاحش ‘) ، записываемый на персидском языке в большинстве контрактов и трактуемый следующим образом: [не допускать условия для кабальной сделки]. Эта фразеологическая единица может поставить в тупик малоопытных переводчиков, так как целое правовое значение не выводится из составляющих слов. Другими словами, при переводе подобных текстов некомпетентная передача смыслов может привести к неудачному переводу.

Современная правовая система Ирана основана на симбиозе римского права и исламской юриспруденции. До исламской революции 1979 года сфера действия исламских юридических законов была очень ограниченной. А исламское право распространялось на область личного статуса. После революции новое государство начало исламизацию правовой системы. В послереволюционной конституции было закреплено положение о приведении всех законов в соответствие 
с шариатом. В связи с этим в некоторых случаях поиск эквивалентов при переводе оказывется сложным, и только через передачу смыслов можно донести смысловую составляющую текста. Например, в брачных документах в Иране в зависимости от формы развода каждой форме присущи определённые названия. Согласно гражданскому кодексу Ирана, ст.1143, существует два вида развода, первый из которых - «Талӓк-е раджии» (طلاق رجعى), то есть предварительный развод [9, с. 201-202]. Данный вид развода прекращает брак не полностью, и при совершении такого вида развода предполагается возможность возвращения в супружескую жизнь на протяжении «иддӓ» (трёх менуструальных периодов), при этом согласия жены не требуется. Разные исламские школы (мазхабы) согласны в том, что при таком виде развода муж вправе возвращаться к супружеской жизни в любой момент срока иддӓ. Следующий вид называется «Талӓк-е бӓин» (طائن) (полн) (пый развод), в соответствии с которым разведённый муж лишается права возобновить расторгнутый брак в срок иддӓ. Исходя из описания вышеуказанных разводов, мы видим, что в одном из них имеются условия, позволяющие разведённым супругам вернуться к супружеской жизни. В судебной системе РФ, прекращение брака ограничено одним видом развода. Конечно, в данной работе мы не намерены описывать правовые условия развода, однако, акцентируясь на вышеуказанных юридических терминах в персидском языке, мы убеждаемся, что перевод правовых норм вызывает трудности, в силу чего переводы не дотягивают до полноценной эквивалентности. Национальные и культурные характеристики, религиозные основы иранцев и россиян имеют существенные различия. Какие эквиваленты могут соответствовать терминам «бӓин» и «раджи»? Понятие «раджи» религиозные эксперты и языковеды интерпретируют как «предварительный», «возвратный», «неполный», среди которых предпочтительным вариантом является «предварительный». А понятие «бӓин» было решено переводить как «полный», что позволяет прояснить одну сторону данного юридического термина и отличать от «раджи», то есть от возможности возобновить расторгнутый брак.

В свою очередь развод бӓин делится на несколько разновидностей. В «Санад-е-талӓк» (سند طلاق) 'свидетельстве о расторжении брака', кроме вышеназванных условий предусмотрен «оджрат алмесл» (اجرت المثل) (возмещение): согласно шариату и закону, при разводе женщина заслуживает награды, называемой возмещением за выполнение всех дел, которые она не была обязана делать в течение своей совместной жизни в доме своего мужа. Такое право предусмотрено с целью поддержки женщин после развода, во избежание финансовых трудностей. Как видим, приведённые выше примеры не имеют эквивалента в русском языке, так как подобная обязанность не возлагается на граждан России.

Касательно несоответствия юридических терминов в русских и персидских текстах, приведём другой пример. В сертификате о регистрации права собственности в иранских документах существует термин, выражающий долю собственности. Слово «Däng» (دانگ), обозначающее одну шестую часть недвижимого/движимого имущества, не имеет эквивалента в русских математических терминах, и только посредством дополнительного объяснения можно выяснить его юридическое значение. Термину «Däng» даётся следующая дефиниция - каждый недвижимый/движимый объект, кроме продовольственных и текстильных объектов, делится на шесть (6) равных частей, каждая часть, в свою очередь, делится на шестнадцать (16) долей. В результате произведения шести частей на шестнадцать долей получаем 96 паев. Иными словами, каждый недвижимый/ движимый объект может иметь от одного до 96 собственников пропорционально разным частям «дӓнг». Вышеуказанные объяснения позволяют раскрыть трудности передачи аналогичных видов юридических текстов. Очевидно, что такого понятия в русских юридических текстах не существует, и только через передачу смыслов представляется возможным донести содержание текста.

Можно привести ещё один пример. Перед заключением договора купли-продажи в Иране оформляют документы, указывающие этапы реализации владения имуществом; то есть перед тем, как регистрировать право собственности на имя нового владельца, подписывают «Gholnämе» (قول نامه), что дословно обозначает 'Письмо-обещание', с подписанием которого офицально вступает в силу передача права собственности покупателю, но в случае возникновения каких-либо проблем, продавец или покупатель вправе расторгнуть договор «Gholnämе» с выплатой штра- 
фов в размере, указанном в «письме-обещании». Сделка считается совершённой подтверждением факта перечисления полной стоимости проданного или купленного объекта. После этого можно регистрировать в ГОРДУН (Государственная Организация Регистрации Документов и Учёта Недвижимости), и в результате право собственности полностью отчуждается в пользу другого лица. Как видим, «Письмо-обещание» носит юридический характер и вызывает юридические последствия, но оно не имеет точного эквивалента в русских юридических текстах, можно только в некоторых случаях консервативно выбрать оборот «Гарантийное письмо», которое по сути содержания отличается.

В юридическом лексиконе Ирана фигурирует термин «Санад» (ذن), значение которого в переводе на русский - «документ», имеющий отношение к большинству официальных документов, включая «Санад-е-эздевӓдж» (سند ازدواج) 'Справка/свидетельство о заключении брака', «Санад-еталӓк» (سند طلاق) 'свидетельство о расторжении брака', «Санад-е хане/мельк» (سند خانه) 'Свидетельство о государственной регистрации права собственности на недвижимое имущество’ "Санад-е машин/мотор» (سند ماثشين/ موتور) Паспорт Транспортного Средства, «Санад-е-чешмандазе бист сале» (ساله سند جشم انداز بيست) 'Документ о перспективах будущего того, кому исполнилось двадцать лет' [6].

Как мы видим, каждый иранский документ, содержащий в наименовании «санад», в российской юриспруденции может переводиться либо как «свидетельство», либо как «паспорт». Переводчик в каждом из подобных случаев должен искать наиболее подходящее соответствие в печатных источниках или в сети Интернет.

В 17.03.2010 г. во исполнение законной обязанности было установлено распоряжение о выдаче одностраничного документа собственности в 17 статьях и 11 примечаниях в пункте Б ст.13 бюджетного закона, в рамках унификации, повышения безопасности и предотвращения фальсификации вышло постановление о внесении сведений о кадастровом номере объекта недвижимости в реестр в форме, называемой «Санад-е-такбарги» (سند تكى برحى), дословно обозначающей «одностраничный документ» [7].

Почему возникло такое наименование? Что следует понимать под одностраничным документом? Без сомнения, дословный перевод на русский язык может показаться забавным. Следующий документ, более авторитетный по сравнению с предыдущими документами, называется «Санадее-мангуледар». Дословно обозначает 'документ со шнурком/ прошивкой. Он отличается по физической структуре от простого прошнуривания, поскольку их выдавал ГОРДУН в форме книжек с железными пломбами с отметкой.

Под термином «Вакф»(وقف), также известным как «Хубус» (حبوس), понимается необлагаемый налогом и не подлежащий конфискации благотворительный дар. Согласно исламскому закону, действие права собственности навеки останавливается: даритель утрачивает его, а получатель не приобретает. Вакф не может переходить по наследству, быть предметом последующих дарений и, как правило, купли-продажи.

Обычно это включает в себя пожертвование здания, участка земли или других активов для благотворительных целей без намерения вернуть имущество. Хорошо известно, что благотворительные пожертвования имеют гораздо более древнюю историю, чем ислам, и весьма вероятно, что исламское право могло базироваться на правовом наследии предыдущих цивилизаций.

Слову «Вакф» присуще несколько вариантов значений, такие как «остановить», «запрещать» и «сохранить», но, как было уже сказано ранее, эти термины не могут быть использованы в качестве эквивалентов. В силу невозможности найти равноценные соответствия, употребляется его оригинальная форма, смысл которой передаётся описательным способом. «При выполнении перевода правовых документов особое внимание должно уделяться лексической безэквивалентности, так как во всех языках существуют слова и устойчивые словосочетания иностранного языка, не имеющие более или менее полных соответствий в виде лексических единиц» $[4$, c. 4]. Переводчику очень важно иметь представление о явлениях такого рода. Проверка смыслового соответствия юридических единиц может быть проведена различными способами, одним из которых можно назвать поиск равнозначных терминов в сети Интернет. Поскольку социальные сети постоянно подпитываются новыми данными и ориентированы на нужды пользователей, мы можем обна- 
ружить эквиваленты персидским юридическим терминам, изучая русскоязычные юридические документы, размещённые в сети Интернет.

\section{Выводы}

Во всех языках мира существуют своеобразные специфические устойчивые словосочетания, не имеющие полного эквивалента в других языках. Перевод любого рода текста требует лингвистических и экстралингвистических навыков. Юридический текст содержит правовую информацию, которую следует стремиться сохранить при переводе.

Перевод функционирует как «опылитель» культур, обогащая одну культуру идеями другой. Более того, юридический перевод служит мостом для взаимопонимания между народами, облегчая решение жизненно важных человеческих проблем. Такой важный инструмент заслуживает более широкого признания как лингвистов, так и юристов. Когда речь идёт о переводе юридических текстов на персидском языке, встречается ряд таких препятствий, как отсутствие специальных юридических словарей и изобилие арабских религиозных терминов, осложняющих работу переводчиков. Переводчик обязан найти в языке перевода наиболее подходящее сочетание или слово, имеющие аналогичные значения. Во избежание упомянутых сложностей, целесообразным будет совместное сотрудничество в составлении специализированных словарей, создание форума для переводчиков специалистов в сфере юридических текстов, где они могли бы обмениваться опытом, что способствовало бы улучшению перевода текстов в данной области. В связи с этим существует большая потребность в реализации совместной программы по созданию переводческих научных обществ с помощью лингвистов, юристов и представителей судебных органов Ирана и России.

(C) Резвани B., 2021

\section{Список литературы}

1. Алексеева И.С. Введение в перевод введение/ И.С. Алексеева : Учеб. пособие для студ. филол. и лингв, фак. высш. учеб. заведений. СПб.: Филологический факультет СПбГУ; М.: Издательский центр «Академия», 2004. 352 с.

2. Гуцу Ю.Э. Особенности перевода юридических терминов/ Ю.Э. Гуцу, Выпускная квалификационная работа магистра, СПБГУ, 2016. 84c.

3. Киндеркнехт А.С. Особенности перевода юридических текстов // Ученые записки Орловского государственного университета. Серия: Гуманитарные и социальные науки. № 5 (68). Орел: Изд-во Орловского гос. ун-та, 2015. С. 123127.

4. Умерова М.В. Особенности перевода документов и текстов официального характера/ М.В Умерова, Актуальные проблемы гуманитарных и естественных наук. 2011. № 12. с. 132-137.

5. Хачатуров Р.Л. О правовой системе Ирана/ Р.Л. Хачатуров, Вектор науки ТГУ. № 6(9). 2009, сс.58-61.

6. https://rc.majlis.ir/fa/law/show/132295- (дата обращения 26.08.2020)

7. https://rc.majlis.ir/en (дата обращения 26.08.2020)

8. FéRailleur-Dumoulim C., A Career in Translation: Insightfull Information to Guide You in Your Journey as a Professional Translator/ C. FéRailleur-Dumoulim Bloomington: AuthorHouse. 2009. pg.34.

9. Mansour, Jahangir, Civil Law with the latest amendments and additions to the Civil Liability Law, Tehran, Didar Publishing, 2010. Pp. 201-202.

\section{References}

1. Alekseeva, I.S. Vedenie v perevodavedenie [Introduction to Translation Studies] / I.S. Alekseeva. M .: Academia, 2006.282 p.

2. Gutsu,Yu. E. Osobennosti perevoda uiridicheskikh terminov [Features of translation of legal terms] / G.Yu. Eduardovna, Master's final qualifying work, St. Petersburg State University, 2016.84p.

3. Kinderknecht, A.S. Osobennosti perevoda iuridicheskikh tekctov [Peculiarities of translation of legal texts] / A.S. Kinderknecht, Philological Sciences M., 2019.p.123.

4. Umerova, M.V. Osobennosti perevoda dokumentov i tekstov ofitcialnogo kharaktera [Peculiarities of translation of documents and texts of an official nature] / M.V. Umerova // Actual problems of the humanities and natural sciences. 2011. No. 12. S. 132-137. 
5. Khachaturov, R.L. O pravovoi sisteme Irana [About legal system of Iran] / R.L. Khachaturov, TSU Science Vector. No. 6 (9). 2009, pp. 58-61.

6. https://rc.majlis.ir/fa/law/show/132295- (accessed date26.08.2020)

7. https://rc.majlis.ir/en дата обращения (accessed date 26.08.2020)

8. FéRailleur-Dumoulim, C. A Career in Translation: Insightful Information to Guide You in Your Journey as a Professional Translator / C. FéRailleur-Dumoulim Bloomington: AuthorHouse. 2009. p.34.

9. Mansour, Jahangir. Civil Law with the latest amendments and additions to the Civil Liability Law, Tehran, Didar Publishing, 2010. Pp. 201-202.

\section{Сведения об авторе:}

Резвани Ваджихе - кандидат филологических наук, ассистент профессора, преподаватель кафедры русского языка, Университета Аль-Захра (г. Тегеран, ИРИ). Сфера научных и профессиональных интересов: грамматика русского языка, переводоведение, лингвокультурология, лексикология.

E-mail: v.rezvani@alzahra.ac.ir

\section{About the author:}

V. Rezvani - Assistant Professor at Department of the Russian Language, Faculty of Literature, Alzahra University, Tehran, Iran. Spheres of research and professional interest: the Russian grammar, translation studies, cultural linguistics, lexicology. E-mail: v.rezvani@alzahra.ac.ir 